\title{
Dynamic Modelling of VFC from 2000 to 2010 Using NDVI and DMSP/OLS Time Series: A Study in Guangdong Province, China
}

\author{
Seyed Omidreza Shobairi, Mingyang $\mathrm{Li}^{*}$ \\ Department of Forest Management, College of Forestry, Nanjing Forestry University, Nanjing, China \\ Email: Omidshobeyri214@gmail.com, "2354363788@qq.com
}

Received 22 February 2016; accepted 22 April 2016; published 25 April 2016

Copyright (C) 2016 by authors and Scientific Research Publishing Inc.

This work is licensed under the Creative Commons Attribution International License (CC BY). http://creativecommons.org/licenses/by/4.0/

(c) $\underset{\mathrm{EY}}{\mathrm{E}}$ Open Access

\begin{abstract}
Forest cover change is considered one of the serious issues in the last several decades for the global environment. This scenario has mainly depended to ever-increasing socio-economic activities. The present article has revealed major changes of VFC in relation to human activities during the years of 2000 to 2010 in the Guangdong province of China. The data derived using the NDVIimages. The analysis covered the growing season which consisted of seven months (April to October) annually. VFC (Vegetation Fractional Cover) was successfully calculated from NDVI images and VFC levels were defined in four levels. Levels IV and I had the highest and lowest annual changes. Areas at risk of desertification and difference coverage were determined by Hot Spot and Cold Spot analyzing. Mean of total VFC was evaluated 0.783 and Moran's I statistic calculated for years separately. Additionally, Light Index achieved of DMSP/OLS data annually. The results show that VFC and Light Index have an upward trend, which means that development of social economy leads to increasing awareness of the importance of environmental protection and sustainable development. Hereof, we witness seven-year increase of VFC during the eleven years. The correlation co-efficient shows that Light Index is suitable index for evaluating diving forces. Time series modeling confirms that there is strong inverse relationship between the VFC and Light Index in most cases. This means with increasing Light Index, VFC decreases. Finally, driving forces of VFC variation show that forest cover change scenario is more under the influence of the human activities.
\end{abstract}

\section{Keywords}

VFC, Light Index, Human Activity, Dynamic

\footnotetext{
${ }^{*}$ Corresponding author.
} 


\section{Introduction}

Global forest cover change due to increased human activities is one of the most important issues in climate change and global warming. It has been especially considerable in the last few decades. Increasing rate of deforestation due to pressure is caused by the population growth and it is very important to compute the trend of global environment as deforestation with the satellites products, meteorological datasets and socio-economic information based on population growth [1]. Use of remote sensing in monitoring forest cover change dates back to the early 1980s [2]. Remote sensing data provide an alternative data source to quantify forest cover. Information is derived from satellite imageries and there are suitable tools for mapping land-cover, tree canopy cover and dominant tree species composition [3]. At the same time, remote sensing-based forest cover change analysis requires less effort and time than ground surveys and can be performed in areas of limited ground access. This is why remote sensing-based products are widely used for multi-national forest assessment and change estimations [4]. Their results showed as a baseline for carbon modeling, fire management and socio-economic analysis as well as for studies of forest cover dynamic and biodiversity patterns [5]. Effective monitoring of forest cover requires longer-term data set with fine spatial resolution ideally at sub-hectare spatial resolutions spanning multiple decades [6]. In this context, satellite borne sensors can detect forest cover change in the visible, thermal and mid-infrared signature during the days, nights, months and seasons [2]. In this study, we use one of the most common satellite systems as MODIS (Moderate Resolution Imaging Spectroradiometer) from NASA which provides visible and thermal images and also it can be evaluated forest cover changes. There are a lot of projects that are defined start and end of the growing season using MODIS-based 16-days NDVI profiles derived within MODIS-based forest cover mask for each Landsat footprint [3]. The growing season was defined as the sum of all 16-day intervals having an NDVI equal to or above $90 \%$ of the maximum annual NDVI. The NDVI images of MODIS (1 month-Terra) from the NEO (Nasa Earth Observations) data archive can be used as based datasets [7]. Using NDVI images are computed Vegetation Fractional Cover. VFC is the vertical projection of vegetation including leaves, stems, and also shoots to the ground surface and is expressed as the fraction or percentage of the reference area [8]. In fact, VFC enables to couple natural environment changes and human activities and also it is an essential index to study the ecological systems [9]. In addition, vegetation change attaches a great importance to global energy circulation and geo-biochemical cycle of substance, thus evaluating VFC contains great significant for both ecology and society exactly [10]. On the other side, DMSP/OLS (Defense Meteorological Satellite Program/Optical Linescan System) datasets from NOAA (National Oceanic and Atmospheric Administration) makes daily over flights and routinely collects visible images during its nighttime pass [11]. In fact, DMSP/OLS is possible to detect human presence, urban settlements and light-demanding activities, estimating urban population and density, socio-economic activities, energy and electricity consumption and gas emissions [12]. Also [13] reported that popular applications of the DMSP/OLS night time images included measuring impacts of urban growth on the environment, mapping nighttime sky brightness and specially evaluating damage from natural disasters and forest fires. Generally data available of DMSP/OLS nighttime images can be present by Nasa Earth Observation and National Center for Environmental Information Archive from NOAA. In this paper, we calculate VFC and VFC levels for a period of eleven years annually. Also, we explain significant cover changes in this period dynamically. In addition, we assess the quality of theforest cover and changes by mean of NDVI, VFC, VFC levels and Hot Spot-Cold Spot maps. We aim to show that DMSP/ OLS images ingeminate population density and human activities dynamically. Totally, this paper demonstrates relationship between Light Index with VFC, to detect trend of VFC changes and Light Index and it describes driving forces of VFC variation in the whole study area during 2000 to 2010. Finally, we discuss about these validation results with each other.

\section{Data Source and Methodology}

\subsection{Study Area}

Figure 1 shows the political map of China with different state boundaries and specially study area. Guangdong is a province on the South China Sea coast of the People's Republic of China. The district occupies an area of $179,800 \mathrm{~km}^{2}$ and it is bounded by $20^{\circ} 13^{\prime}-25^{\circ} 31^{\prime}$ North latitudes and $109^{\circ} 39^{\prime}-117^{\circ} 19^{\prime}$ East longitudes. Guangdong neighbors Jiangxi and Hunan provinces in the north, Fujian province in the east, and the Guangxi Zhuang autonomous region in the west. The provincial capital Guangzhou and economic hub Shenzhen are among the 


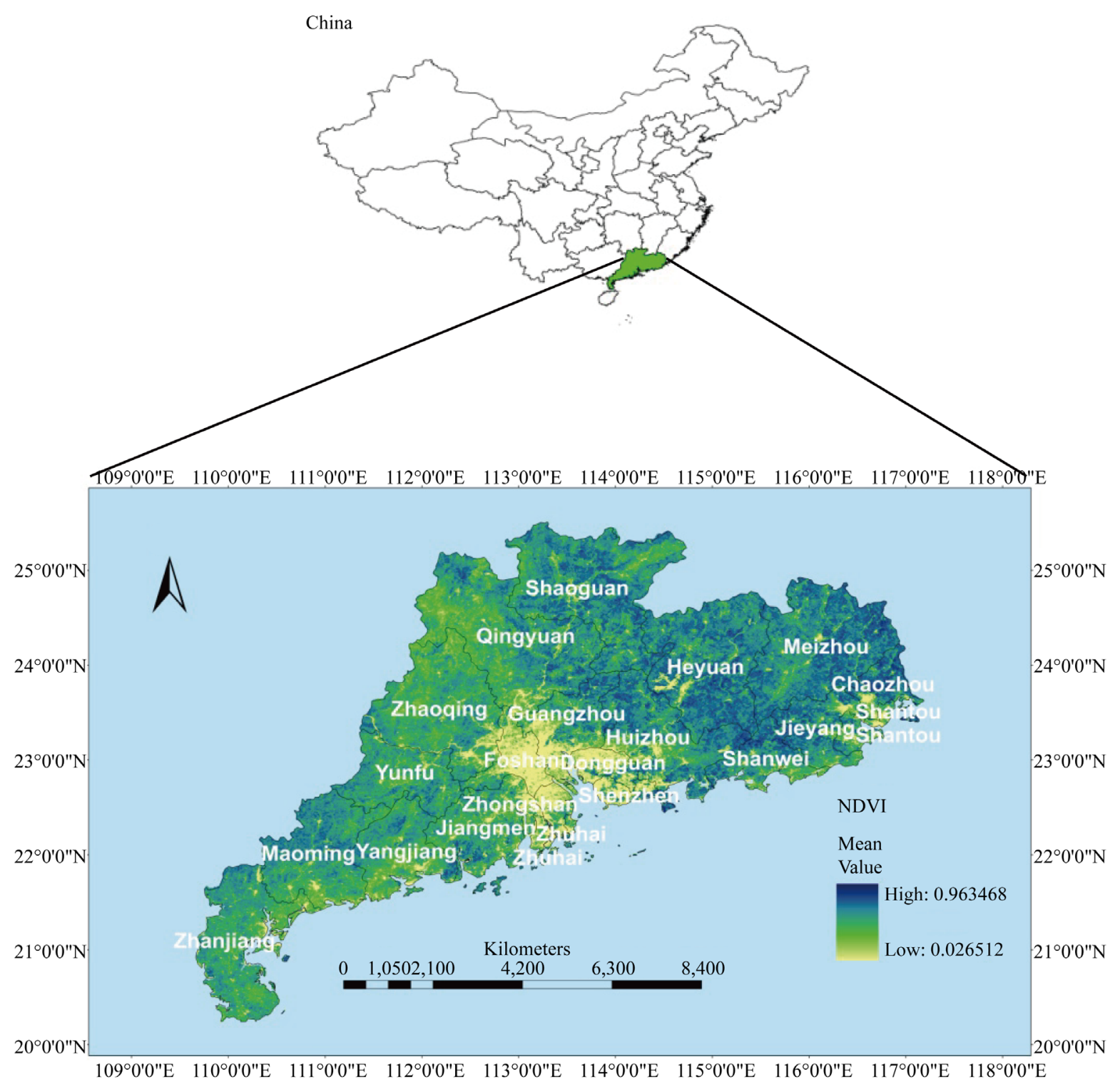

Figure 1. Location map of Guangdong province, China (noted; used index is NDVI dynamics in 2005).

most populous and important cities in China. The Guangdong had 106,440,000 people in 2013 and it to have followed many economic and social developments. Guangdong province is divided into 21 prefecture-level cities, 33 county-level cities, 43 counties and 3 autonomous counties [14]. Crossed by the tropic of Cancer in the central part of its continental portion, tropical and sub-tropical Guangdong has a climate marked by high temperature and plentiful rainfall. It has the highest mean temperature of $28^{\circ} \mathrm{C}$ in July (the hottest month in a year) and $13^{\circ} \mathrm{C}$ in January (the coldest month in a year). The greater part of the province has a mean annual precipitation of about 1500 - $2000 \mathrm{~mm}$ and with 140 - 160 rainy days. Guangdong province has vegetation varies from north to south. In the north, the Nanling Mountain Ranges is covered by the subtropical montane evergreen broadleaved forest; in the middle, it is the subtropical evergreen broadleaved forest, and in the south the tropical monsoon forest. Guangdong abounds in the fauna and flora resources; there are more than 7055 species of vascular plant here, 4000 species of which are woody plant or $80 \%$ of the total woody plant in China [15].

\subsection{Satellite Data and Data Processing}

The selection of first images whit minimizing phonological or atmospheric noise was performed from the web- 
site of NEO datasets [16], by appropriate based on phonological time series of NDVI from the MODerateresolution Spectroradiometer (MODIS) [17]. Desired data were selected from the start and end of the growing season from April to October (seven months) and MODIS-based 16-days NDVI was confirmed from 2000 to 2010. These data will improve our understanding of global dynamics and processes occurring on the land, in the oceans, and in the lower atmosphere. MODIS is playing a vital role in the development of validated, global, interactive Earth system models able to predict global change accurately enough to assist policy makers in making sound decisions concerning the protection of our environment. The second datasets were DMSP/OLS nighttime data from 2000 to 2010 with operating F14, F 15 and F 16 satellites in sun synchronous orbits with nighttime overpasses ranging from nearly $8 \mathrm{pm}$ to $10 \mathrm{pm}$ local time. The images were obtained from the web site of NOAA [18] directly. Given the sensitivity of the sensor at night, DMSP/OLS data can be used to detect a variety of VNIR emissions. The availability of long time data with moderate spatial resolution (e.g., $1 \mathrm{~km}$ ) has enabled researchers to explore a series of global, national and regional research subjects. DMSP/OLS nighttime have been used to directly observe natural phenomena (e.g., forest fires) and evaluate social, demographic and environment changes in lit areas [13]. Figure 2 shows the general framework of methodology followed in this study. Details of the various steps are discussed in the following sections.

There are different methods of Geography Information System (GIS) based models to evaluate VFC changes. The growth condition of forest vegetation is calculated basically through vegetation index. Different vegetation index measures the relationship between vegetation growth condition and spatial distribution from different angles [19]. In order to obtain the correct result and also to avoid errors and miscalculations, this method was used as follow; this phase, according to growing season in our study (April to October), extracted by mask of MODIS NDVI images was calculated using ArcMAP desktop during one year. In addition, this operation was calculated for a period of 11 years completely (from 2000 to 2010). Studies have been shown that the growth condition of forest vegetation is measured mainly through vegetation index [10]; So NDVI was used in this paper, because it is sensitive to the growth status and spatial distribution of green plants [8]. Equation (1) is as follow;

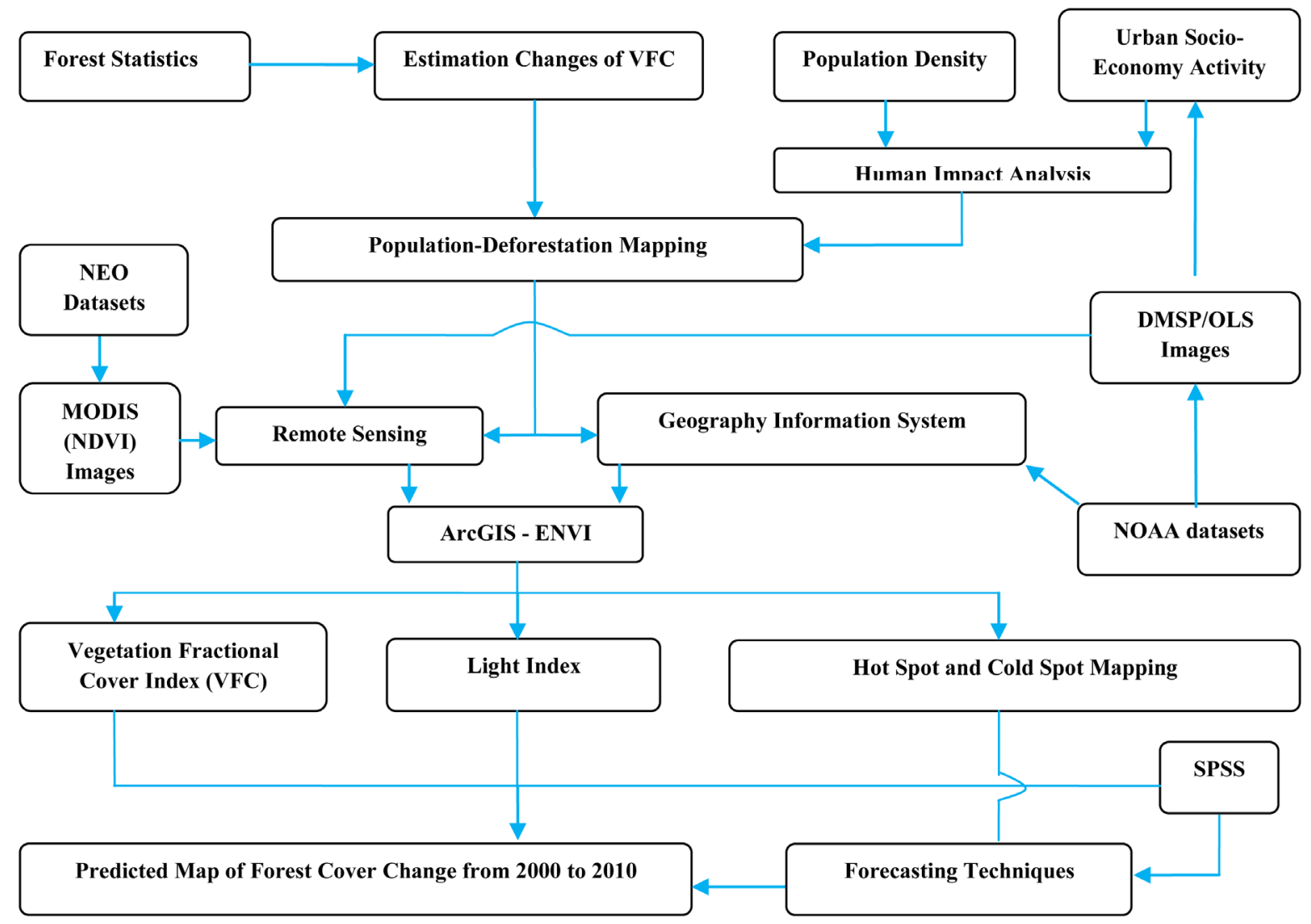

Figure 2. Framework of the methodology adapted to predict forest cover change dynamically. 


$$
N D V I=\frac{N I R-V I S}{N I R+V I S}
$$

With the help of Cell Statistic the Mean values of NDVI images were completely obtained for growing season annually and in addition for the whole period. Then using Raster Calculator, we could calculate the values of VFC for our study period additionally. Equation (2) is as follows;

$$
V F C=\frac{N D V I-N D V I_{\min }}{N D V I_{\max }-N D V I_{\min }}
$$

Among many forest structure variables, vegetation fractional cover, defined as the fractional area (projected vertically) of vegetation canopy occupying a given land area [9], is a key parameter for modeling the exchanges of carbon on the land surface and for monitoring urban environment and urban growth [10]. The amounts of VFC were classified in four levels. Table 1 shows the classification of VFC in four different levels as follows.

Next phase was included making Generate Regular Points with defined value, Clip features, Intersect Point Tool with Calculation, evaluating of spatial autocorrelation and computing Moran's I statistic, and Z score, calculating of Trend and RMSE, computing Cluster and Outlier Analysis (Anselin Local Moran's I statistic) and finally detection of cover changes was evaluated by mapping of VFC, VFC levels, Hot Spot-Cold Spot and DMSP/OLS. All mentioned maps were found the trends of VFC, and other changes with distinctive colors in the study area dynamically. Equation (3) belongs to Moran's I statistic is as follows;

$$
I=\frac{n}{S o} \frac{\sum_{i=1}^{n} \sum_{j=1}^{n} w i, j z i z j}{\sum_{i=1}^{n} z_{i}^{2}}
$$

where $z_{i}$ is the deviation of an attribute for feature $i$ from its mean $(x i-\bar{X}), w i, j$ is the spatial weight between feature iand $j, n$ is equal to the number of features, and So is the aggregate of all the spatial weights:

$$
\text { So }=\sum_{i=1}^{n} \sum_{j=1}^{n} w i, j
$$

The $z_{l}$ - score for the statistic is computed as:

$$
z I=\frac{I-E[I]}{\sqrt{V[I]}}
$$

where:

$$
\begin{aligned}
& E[I]=-1 /(n-1) \\
& V[I]=E\left[I^{2}\right]-E[I]^{2}
\end{aligned}
$$

Besides it can be described at this stage that Equation (8) and definition of Root mean squared error (RMSE) is as follows;

$$
R M S E=\sqrt{\frac{\sum_{i=1}^{n}\left(x_{\text {predicted }, i}-x_{\text {observed }, i}\right)^{2}}{n}}
$$

Table 1. Types of VFC levels and description.

\begin{tabular}{ccc}
\hline VFC levels & \multicolumn{1}{c}{ Type } & Description \\
\hline Level I & Low cover & VFC is less than $50 \%$; open forest land and forestland with low canopy density \\
Level II & VFC is between $50 \%$ to $70 \%$; forestland with medium canopy density \\
Level III & VFC igh cover & VFC is more than $90 \%$; dense woodland and extremely high-yield grassland \\
\hline
\end{tabular}


where $x_{\text {predicted }_{i}}$ is the $i$-th predicted value, $x_{\text {observed }_{i}}$ is the $i$-th observed value in the field survey data, and $n$ is the number of measurements. The root mean squared error also called the root mean square deviation; RMSD is a frequently used measure of the difference between values predicted by a model and the values actually observed in the field survey. These individual differences are also called residuals, and the RMSE severs to aggregate them into a single measure of predictive power. The lower the RMSE value is, the higher the prediction accuracy of the model. On the other hand with a short definition of the concept of Hot Spot and Cold Spot, this methodology is completed. The definition of Hot Spot and Cold Spot Analysis known as Getis-Ord $G_{i}{ }^{*}$-The resultant z-scores and p-values tell you where features with either high or low values cluster spatially. This tool works by looking at each feature within the context of neighboring features. A feature with a high value is interesting by may not be a statistically significant hot spot. To be a statistically significant hot spot, a feature will have a high value and be surrounded by other features with high values as well. The local sum for a feature and its neighbors is compared proportionally to the sum of all features; when the local sum is very different from the expected local sum, and that difference is too large to be the result of random choice statistically significant z-score results. The $G_{i}{ }^{*}$ statistic returned for each feature in the dataset is a z-score. For statistically significant positive z-scores, the larger the z-score is, the more intense clustering of high values (hot spot). For statistically significant negative z-scores, the smaller the $\mathrm{z}$-score is, the more intense the clustering of low values (cold spot). Its formula is as follows; the Getis-Ord local Equation (9) is given as:

$$
G_{i}^{*}=\frac{\sum_{i=1}^{n} w_{i, j} x_{j}-\bar{X} \sum_{j=1}^{n} w_{i, j}}{S \sqrt{\frac{\left[n \sum_{j=1}^{n} w_{i, j}^{2}-\left(\sum_{j=1}^{n} w_{i, j}\right)^{2}\right]}{n-1}}}
$$

where $x_{j}$ is the attribute value for feature $j, w_{i, j}$ is the spatial weight between feature $i$ and $j, n$ is equal to total number or features and:

$$
\begin{aligned}
& \bar{X}=\frac{\sum_{j=1}^{n} X_{j}}{n} \\
& S=\sqrt{\frac{\sum_{j=1}^{n} x_{j}^{2}}{n}-(\bar{X})^{2}}
\end{aligned}
$$

The $G_{i}^{*}$ statistic is a z-score so no further calculations are required. In this section total Mean of VFC with minimum value of RMSE was completely calculated for the whole period and map was designed symbolic with four colors for better understanding of VFC levels and prediction of trends changes. In the fourth phase, our study area (Guangdong province) was extracted from DMSP/OLS images annually and Mean values of DMSP/ OLS were calculated from 2000 to 2010. Then in other to achieve better results, according to Attribute Table and Zonal Statistic operation; were computed original values of Min, Mean, Max, Range, Sum, Standard Deviation and etc of DMSP/OLS images in the study area repeatedly. According to analyze the dynamics of human activities in Guangdong province, the Light Index was calculated during 2000 to 2010 additionally. Light Index takes two parameters as night light brightness and lit urban areas into account simultaneously. The former is closely correlated with urban population and economic scale and the latter is closely correlated with urban area, Therefore changes in the Light Index can reflect the dynamics of urban population size, economic scale, and urban expansion simultaneously [20]. We computed the Light Index at the scale of our study area using the following Equation (12):

$$
\text { Light Index }=I \times S
$$

where $I$ is the average night light brightness of all lit pixels in a region. Equation (13) illustrates as follows:

$$
I=\frac{1}{N_{L} \times D N_{M}} \times \sum_{i=P}^{D N_{M}}\left(D N_{i} \times n_{i}\right)
$$

where $D N_{i}$ is the $D N$ value of the $i$ th gray level, $N_{i}$ is the number of lit pixels belonging to the ithgray level, $P$ is the optimal threshold to extract the lighted urban area from the DMSP/OLS images. $D N_{M}$ is the maximum 
$D N$ value, and $N_{L}$ is the number of lit pixels with a $D N$ value between $P$ and $D N_{M}$. $S$ is the proportion of lit urban areas to the total area of a region. Equation (14) can be showed as follows:

$$
S=\frac{\text { Area }_{N}}{\text { Area }}
$$

where $\mathrm{Area}_{N}$ is the area of lit urban areas in a region and Area is the total area of the region. Finally according to VFC and Light Index, were completely predicted time series modeling. The operation of Correlation Coefficient, Sequence Charts, Time Series Modeler, Autocorrelation and Cross-Correlation Coefficient were directly computed in the SPSS. Also was studied relationship between the VFC and Light Index, and eventually created the best results and intelligible charts.

\section{Results and Discussion}

\subsection{Accuracy Calculation of VFC Dynamic and Change Detection}

According to Table 1, it is seen VFC is divided to four levels such as level I, level II, level III and level IV. Level I has low cover ( $<50 \%)$, Level II includes medium cover $(50 \%-70 \%)$, Level III consists of high cover (70\% - 90\%) and level IV makes very high cover (>90\%). Table 2, shows the values of VFC levels for all years in our study period annually. Level IV has highest mean of change annually between $3.89 \%$ to $21.44 \%$ and level I has the lowest rate among all levels. Level II varies between $7.79 \%$ and $19 \%$ and level III is between $68.38 \%$ and $77.25 \%$. On the other hand level I has lowest mean of change annually, it means this level only occupied 2.37\% of our study area in 2009 and level III has highest rate and it also defines that level III formed $79.42 \%$ of the total study area in 2008. In this way, all regions identify with low to very high coverage and also degraded area and healthy area can be clear during the period correctly. Furthermore Table 2 exhibits values of the other indicators such as Moran are I, RMSE, Mean of VFC, Mean of DMSP/OLS and Light Index annually. Moran's I shows mean annual changes in the growing season. Moran's Thas spatial similarity with significant level of 95\% and also has highest spatial autocorrelation during the months from April to October. The lowest value of RMS error is 0.109 and belongs to 2001 and highest value of RMS error with 0.125 is related to 2006 exactly (Table 2). The root mean squared error is a frequently used measure of the difference between values predicted by a model and the values actually observed in the field survey. These individual differences about RMSE in the Table 2 are also called residuals, and they sever to aggregate them into a single measure of predictive power. The

Table 2. Changes matrix of VFC levels and some important index in Guangdong province from 2000 to 2010.

\begin{tabular}{|c|c|c|c|c|c|c|c|c|c|}
\hline Year & $\begin{array}{l}\text { Level I of } \\
\text { VFC (\%) }\end{array}$ & $\begin{array}{c}\text { Level II of } \\
\text { VFC } \\
(\%)\end{array}$ & $\begin{array}{c}\text { Level III of } \\
\text { VFC } \\
(\%)\end{array}$ & $\begin{array}{c}\text { Level IV of } \\
\text { VFC } \\
(\%)\end{array}$ & $\begin{array}{l}\text { Moran's I } \\
\text { Index }\end{array}$ & RMS Error & $\begin{array}{c}\text { Mean of } \\
\text { Vegetation } \\
\text { Fractional } \\
\text { Cover (VFC) }\end{array}$ & $\begin{array}{c}\text { Mean of } \\
\text { DMSP/OLS }\end{array}$ & Light Index \\
\hline 2000 & 3.42 & 15.74 & 72.78 & 8.05 & 0.29 & 0.118 & 0.771 & 13.925 & 6.55 \\
\hline 2001 & 3.77 & 19 & 73.32 & 3.89 & 0.38 & 0.109 & 0.751 & 13.652 & 6.57 \\
\hline 2002 & 3.05 & 11.65 & 77.25 & 8.02 & 0.34 & 0.112 & 0.785 & 14.234 & 7.13 \\
\hline 2003 & 2.76 & 9.78 & 73.84 & 13.61 & 0.37 & 0.111 & 0.802 & 12.047 & 6.2 \\
\hline 2004 & 3.31 & 10.04 & 75.71 & 10.92 & 0.36 & 0.117 & 0.794 & 14.002 & 7.7 \\
\hline 2005 & 4.04 & 13.26 & 75.86 & 6.82 & 0.36 & 0.119 & 0.772 & 13.002 & 6.23 \\
\hline 2006 & 4.27 & 10.81 & 75.85 & 9.05 & 0.38 & 0.125 & 0.786 & 14.163 & 7.15 \\
\hline 2007 & 3.39 & 9.87 & 76.68 & 10.04 & 0.32 & 0.118 & 0.791 & 14.871 & 8.26 \\
\hline 2008 & 3.93 & 11.55 & 79.42 & 5.08 & 0.36 & 0.119 & 0.775 & 16.497 & 8.28 \\
\hline 2009 & 2.37 & 7.79 & 68.38 & 21.44 & 0.33 & 0.112 & 0.823 & 17.864 & 7.64 \\
\hline 2010 & 4.39 & 12.45 & 75.84 & 7.3 & 0.4 & 0.120 & 0.776 & 18.595 & 9.88 \\
\hline
\end{tabular}

Note: VFC mean vegetation fractional cover; Moran’s I and RMS error belong to spatial autocorrelation and trend of VFC. 
lower RMSE value is the higher of prediction accuracy of the model. RMSE value has higher the evaluation accuracy of our results in 2006. According to the Table 2, lowest and highest of Mean value of VFC are 0.751 $\mathrm{Mg} / \mathrm{ha}$ and $0.823 \mathrm{Mg} / \mathrm{ha}$ in 2001 and 2009 respectively. Beside Mean values of DMSP/OLS and specially Light Index have 12.047 and 6.2 as lowest values in 2003, and have 18.595 and 9.88 as highest values in 2010 exactly. Figure 3 shows trends of VFC levels from 2000 to 2010 clearly. Level I with Low cover $(<50 \%)$ has the fewest changes, level II with medium cover (50\% - 70\%) and also level III with high cover ( $70 \%$ - 90\%) have significant changes and finally level IV with very high cover $(>90 \%)$ has highest changes between all levels [21]. They explained the spatial distribution of VFC indicated that the oasis is mostly occupied by level I and II, amounting for more than $1 / 2$ of the total area. Up to $1 / 3$ of the oasis is occupied by level III and IV. they reported that from 1989-2006, levels I and II average annual change rates increased to $0.891 \%$ and decreased to $1.104 \%$, respectively, and showing the largest average annual change during the period. Finally they concluded the smallest change is related to level $\mathrm{V}$, with only a variation of $0.008 \%$. So, the results of their study are someway consistent with the results of this paper.

According to Figure 4, the spatial autocorrelation of VFC was computed using Moran's I statistic in the study area. Moran's $I$ is applied to evaluate whether neigh boring areas are more similar than would be expected under the null hypothesis [9]. Negative values indicate negative spatial autocorrelation and the inverse for positive values. Value of Moran's $I$ Index varies -1 (indicating perfect dispersion) to +1 (perfect correlation). In fact Figure 4 shows dynamics of VFC changes with lowest amount, that related to 2000 and highest amount that depends on 2010. During the years of 2000, 2002, 2007 and 2009 human activities have been increased and land use changes (Level I of VFC) was dominating on the study area, but in the terms of 2001, 2003, 2006, 2008 and 2010 this trend progressed to afforestation, to restore forest and grasslands and ecological protection. Totally Figure 4 confirms the trend of VFC changes.

The spatial and temporal changes of forest cover, land use and land cover for the years of 2000, 2005 and 2010 has been shown in Figures 5-7 respectively. The forest, farm, grassland, and especially urban has been found. The differences between land uses are because of fragmentation degree, classification and their spatial variations. According to Figures 5-7, indicators as Mean of NDVI (A), VFC (B), VFC levels (C), Cold Spot (D), and DMSP/OLS (A) in Figure 8; the predominant land use (level I of VFC) have occurred almost in the centralsouthern parts of Guangdong province. It surrounded areas such as Foshan, Guangzhou, Dongguan, Shenzhen,

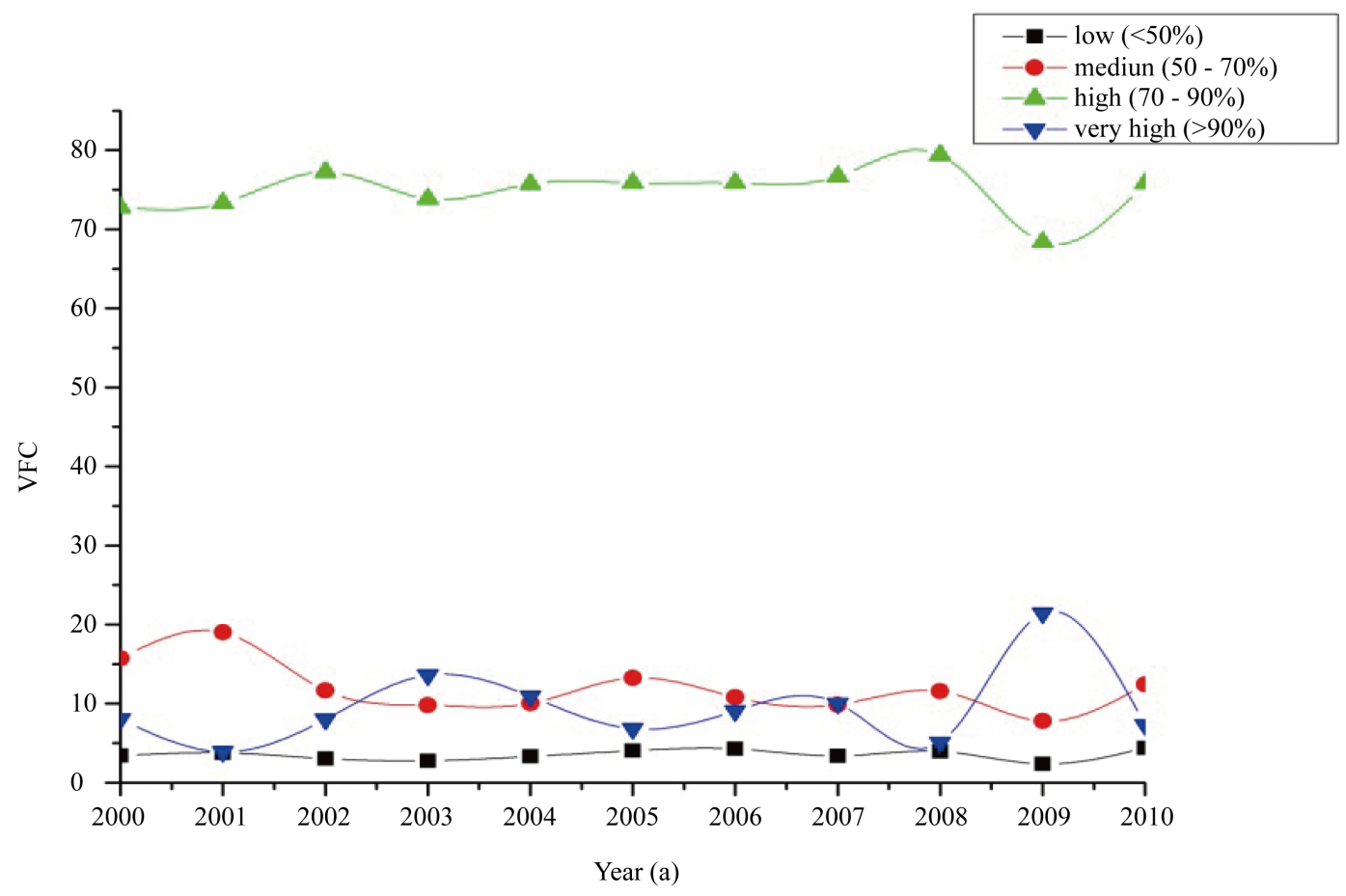

Figure 3. Trends of VFC levels in Guangdong province from 2000 to 2010. 


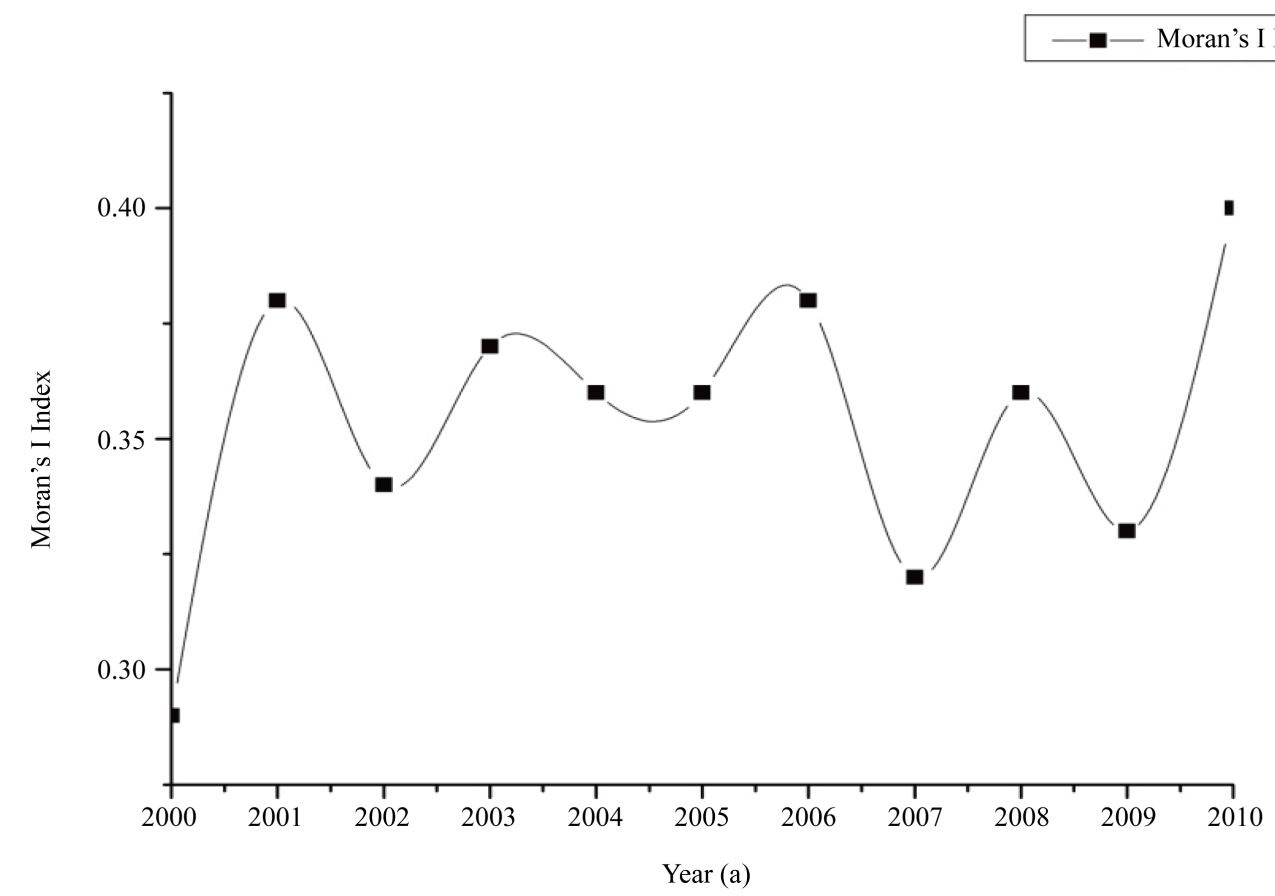

Figure 4. Dynamic of Moran’s I of VFC in Guangdong province from 2000 to 2010.
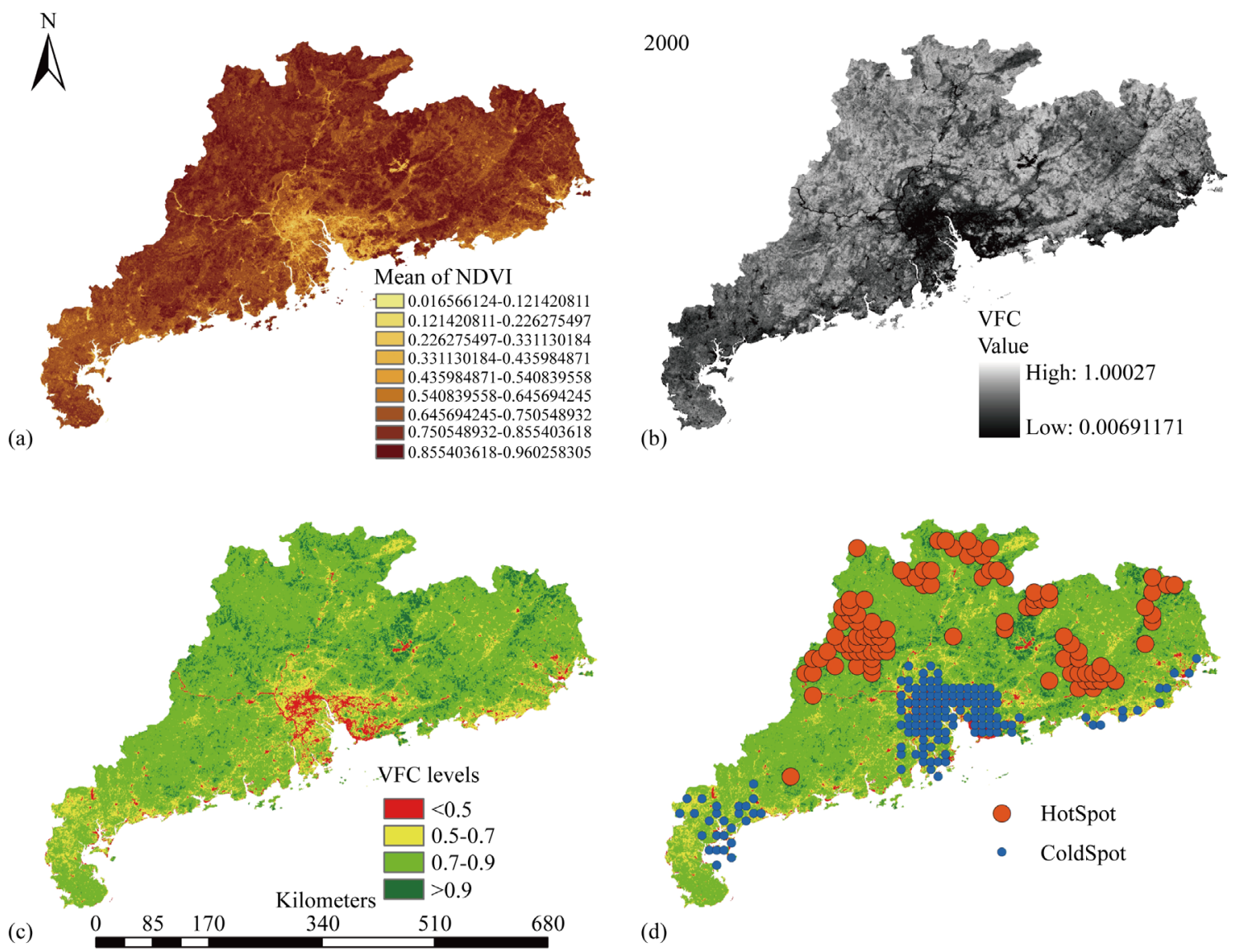

Figure 5. Detection of vegetation coverage changes using Mean of NDVI (a), VFC (b), VFC levels (c), Hot Spot and Cold Spot (d), during the period of 2000, Guangdong province. 

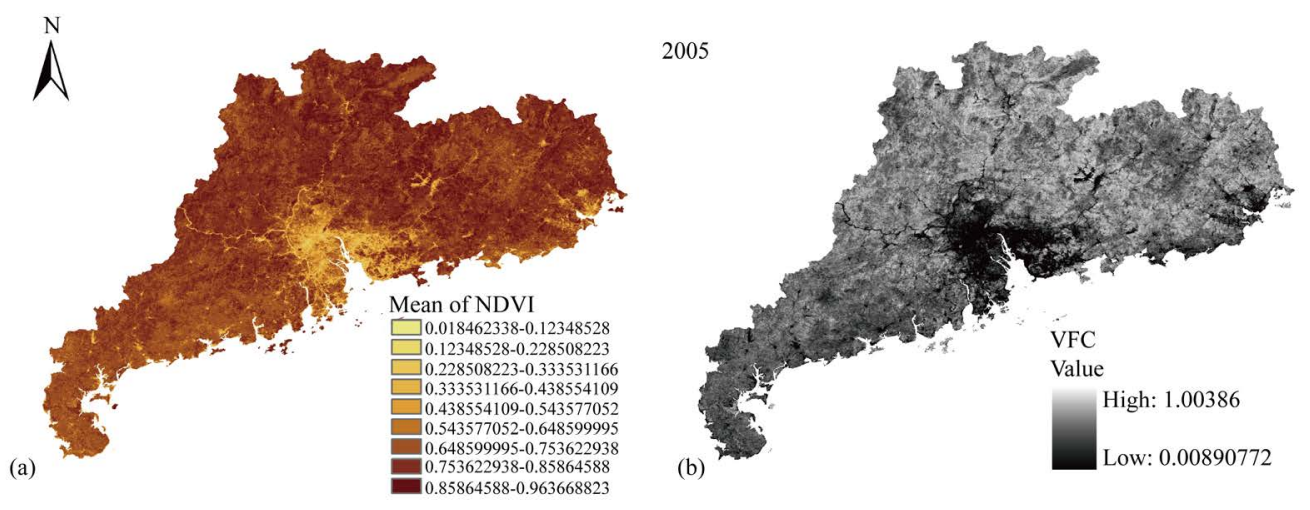

(c)
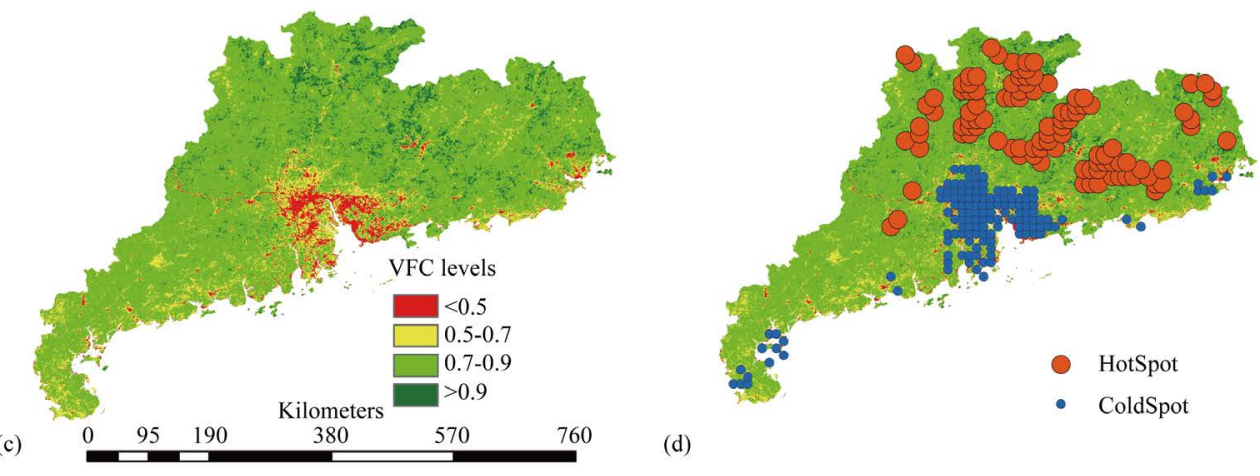

(d)

Figure 6. Detection of vegetation coverage changes using Mean of NDVI (a), VFC (b), VFC levels (c), Hot Spot and Cold Spot (d), during the period of 2005, Guangdong province.
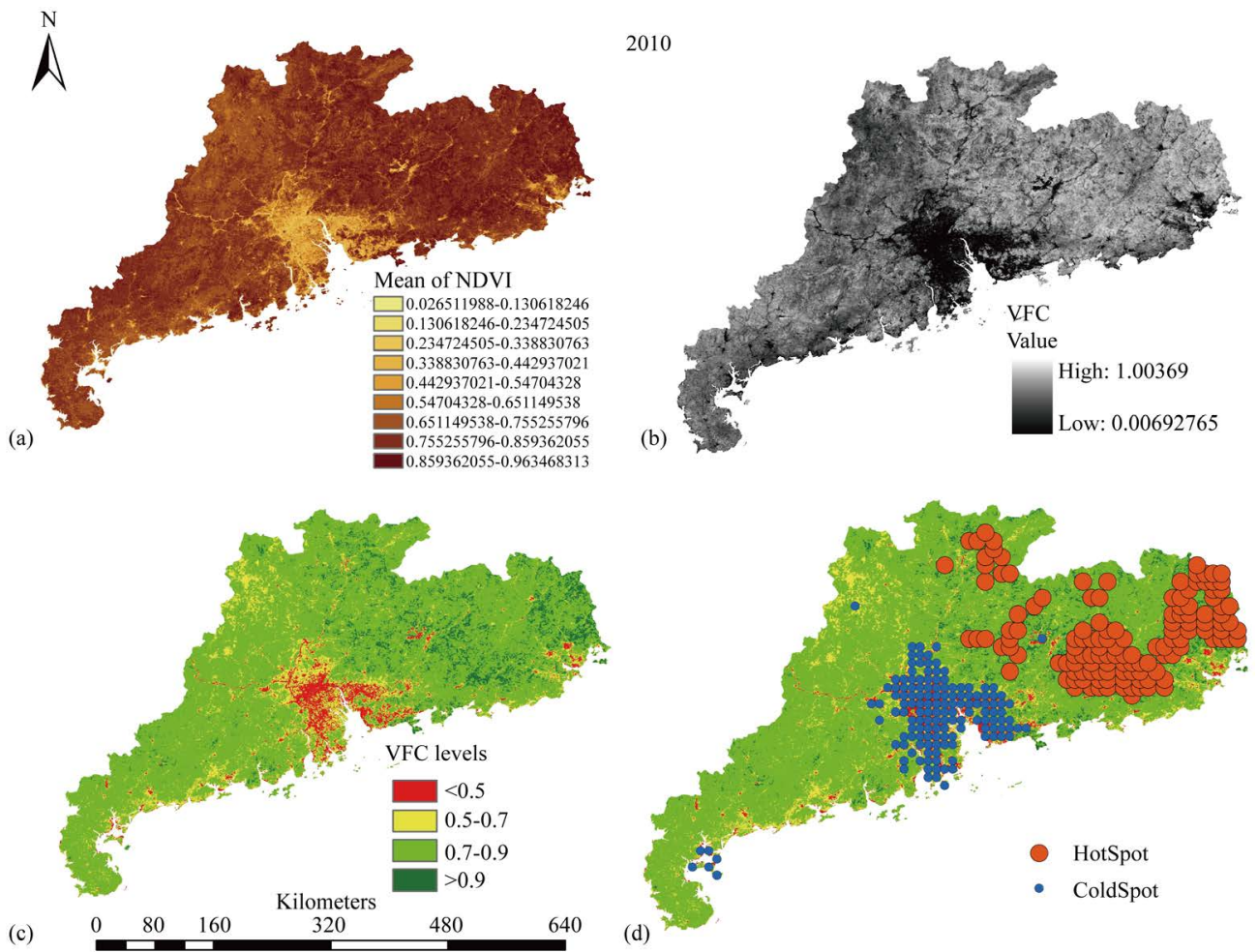

Figure 7. Detection of vegetation coverage changes using Mean of NDVI (a), VFC (b), VFC levels (c), Hot Spot and Cold Spot (d), during the period of 2010, Guangdong province. 

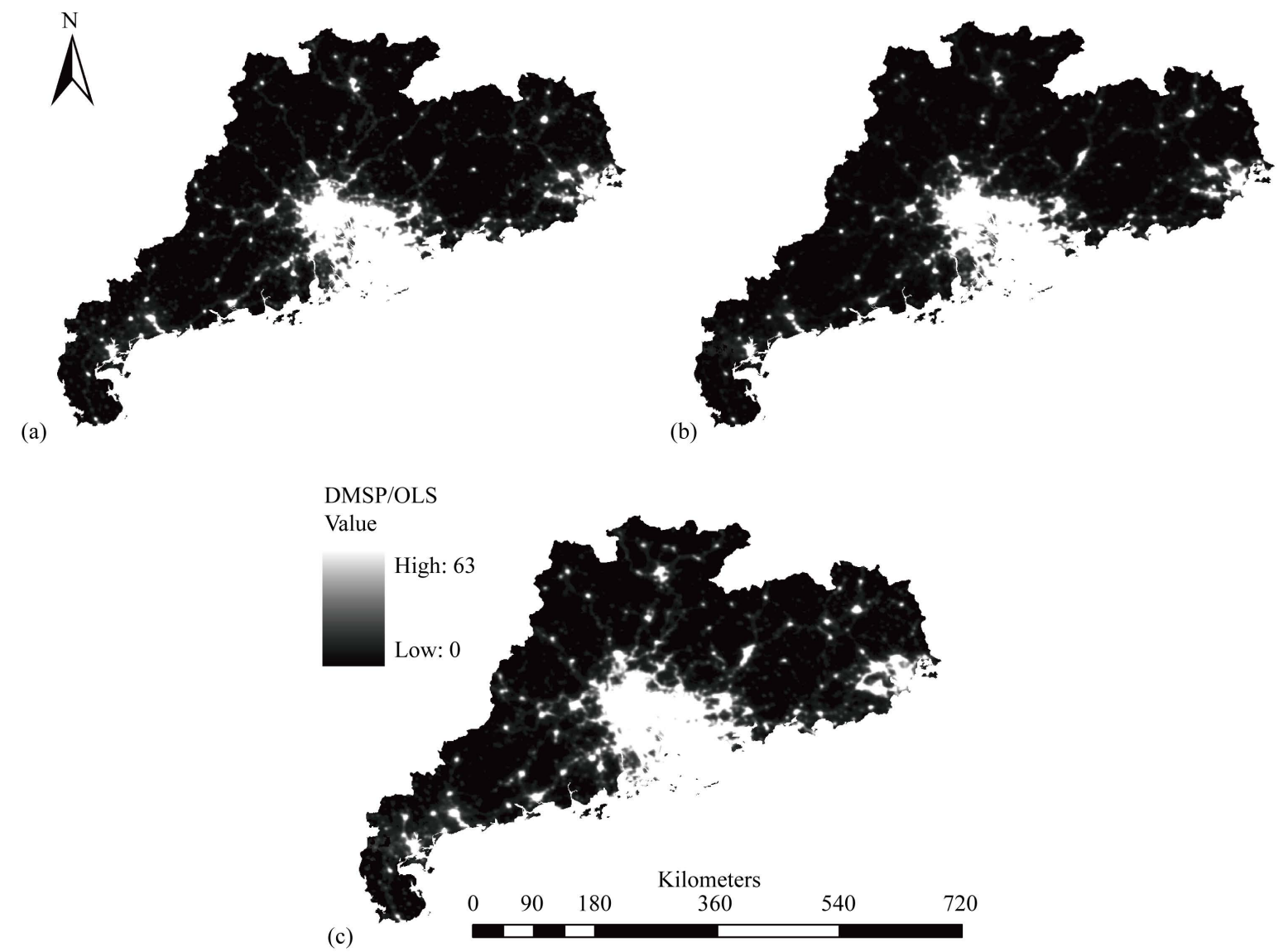

Figure 8. DMSP/OLS changes during the period of 2000 (a), 2005 (b), and 2010 (c).

Zhuzai regrettably. We are also faced with the erosion of coverage in Shantou and Jieyang located in the southeast, and Yangjiang and Zhanjiang in the western areas of Guangdong province during the period of 2000 to 2005. On the other hand with looking in Figures 5-8 and to investigate indicators Hot Spot-Cold Spot (D), it is clear that the clear cutting stopped in the southwest areas such as Yangjiang and Zhanjiang and also in the southeast areas such as Shantou and Jieyang completely. It has been a decreasing trend during the period of 2005 to 2010.Again Figures 5-7 enable to show VFCwith different dynamics clearly. Mentioned indicators as Mean of NDVI (A), VFC (B), VFC levels (C), Hot Spot-Cold Spot (D) restate that high and very high forest cover include level III and IV of VFC, to exist in the north of study area such as Shaoguan and Qingyuan area, in the west such as Maoming, Zhaoqing and Yunfu area and besides in the east of Guangdong province such as Heyuan, Meizhou and Chaozhou area during the period of 2000 to 2005, But mentioned levels of forest cover were more concentrated in the east such as Heyyuan, Shanwei, Jieyang, Meizhou, and Chaozhou area. Furthermore Figure 6 and Figure 7 show that there was significant forest coverage in the northeast part like Qingyuan, Shoaguan area during the period of 2005 to 2010. It should be noted that the spatial Hot Spot-Cold Spot detection attempts to study the sub-regions with attribute values significantly different from other regions in the Guangdong province, which are considered to be the abnormal regions, such as the regions with low or very low coverage as level I of VFC or level IV with very high VFC. Actually importance of Hot Spot-Cold Spot (D) returns to spatial aggregation of the standard deviation (SD) of VFC by 4 types definitions such as high value points (Hot Spot; HH), low value points (Cold Spots; LL) and additionally with high value surrounded by low value points (HL) and points with low value surrounded by high value points (LH). So areas with low coverage (Level I of VFC) are LL briefly and areas with very high coverage (level IV of VFC) are HH. The process of urbanization and human socio-economic activities can be determined by viewing DMSP/OLS changes in Figure 8 in study area during the period of the 2000 (A), 2005 (B) and 2010 (C). This process is increasing from one period to another and also has upward trend annually. DMSP/OLS changes were more dominated in the central- 
southern parts and coastal area of the study area totally. It is clear that Light Index is closely related with Cold Spot statistic, and both of them are important indicators for evaluating of the trend of human activities as urbanization, mine, agriculture and evaluating population density in mentioned figures.

At the bottom, Figure 9 shows total VFC for the whole period from 2000 to 2010 in the Guangdong province. Total VFC divided into four levels symbolically. In this classification level I has red color and includes low cover $(<50 \%)$, level II has yellow color and forms medium cover (50\% - 70\%), level III has light green color and includes high cover (70\% - 90\%) and finally level IV has dark green color and consist of very high cover $(>90 \%)$. The RMS error, Chi-Square and Mean of total VFC are 0.122, 23.1 and 0.783 respectively. As well as we conclude that low forest coverage was occupied central and southern parts of Guangdong. But on the other hand high and very high forest cover are visible in parts of the north, northwest and northeast fortunately. Middle parts are covered with moderate coverage.

\subsection{Relationship, Correlation Analysis and Time Series Modeling}

Table 3 shows results of single correlation analysis between VFC and three urbanization index such as Built up, People city and Light Index. People city and Light Index has relatively strong correlation with the trend of Built up on the whole area of Guangdong province. However a correlation between Mean of VFC and Built up is weak. On the other hand, correlation coefficients of 3 factors with the Built up are relatively large especially in People city and Light Index. Correlation coefficient of mean of VFC decreases, because percent of Built up is very low in the forest area. Table 4 presents total trend of three urbanization index with Light Index and VFC dynamic annually. In general, the trend is increasing and with increasing amounts of urbanization index, values of Light Index and VFC increase. Thus it can be concluded that urbanization index such as dynamic population, city people, road and building distribution are in connection with Light Index and in totally will be affected VFC directly or indirectly. For example, Table 4 shows that amounts of Buid up, Non-agriculture, City People, Light Index and Mean of VFC are 7.946035\%, 0.908174561\%, 0.31185087\%, 6.550127\% and $0.771992243 \%$ in 2000 respectively. These amounts with some increase are 8.136325\%, 0.936682778\%, 0.45834674\%, 6.24091\% and

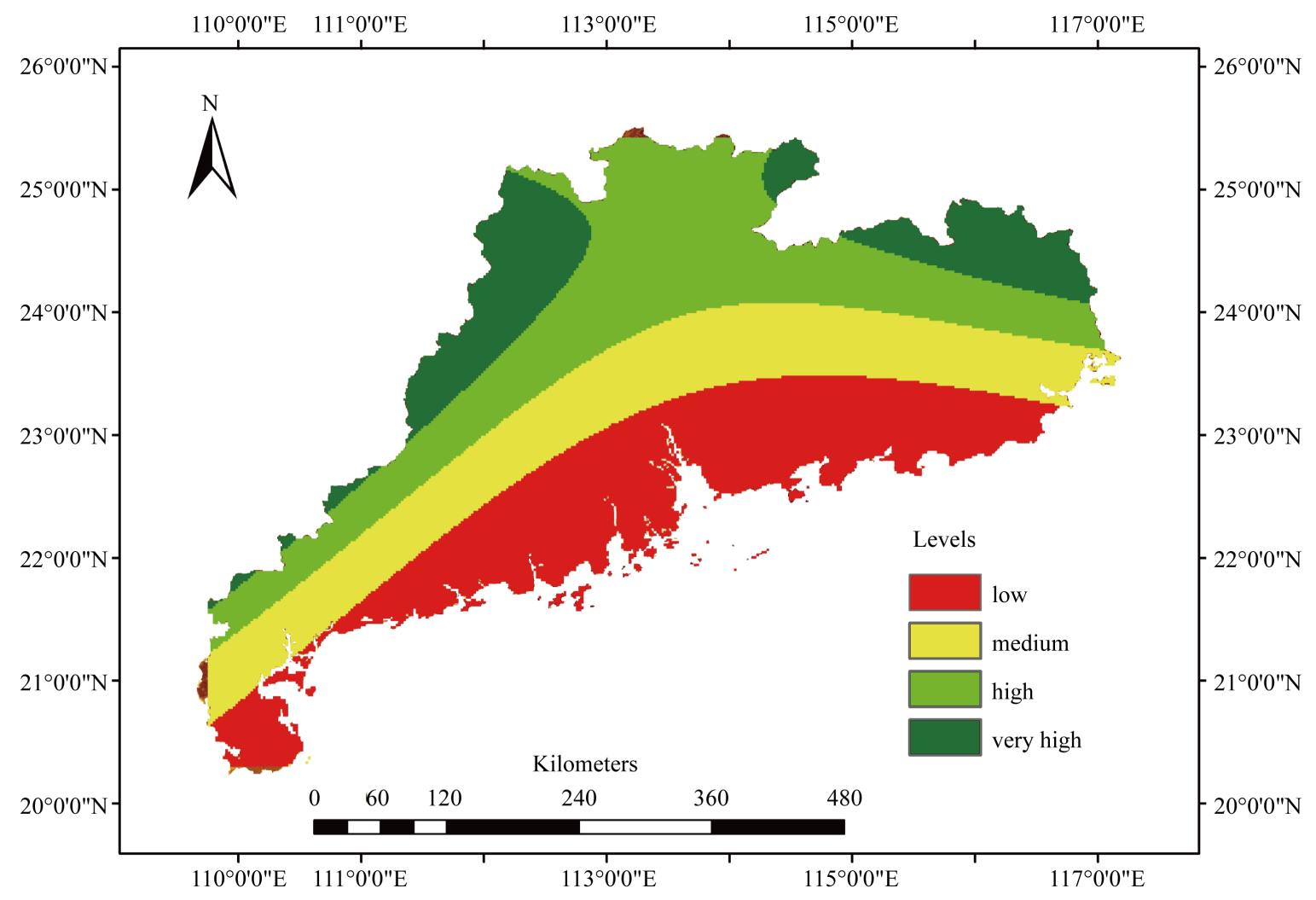

Figure 9. Total VFC for entire period from 2000 to 2010 in Guangdong province. 
Table 3. Correlation between VFC and three urbanization index.

\begin{tabular}{cccccc}
\hline & Built-Up\% & Two Third\% & People City\% & Light Index & Mean of VFC \\
\hline Built Up\% & 1 & & & & \\
Non-Agriculture \% & 0.783206156 & 1 & 1 & 1 & 1 \\
City People\% & 0.715862175 & 0.520838687 & 0.6112 & 0.0881178 & 1 \\
Light Index & 0.880536569 & 0.683332326 & 0.393961 & & \\
Mean of VFC & 0.369019871 & 0.471508065 & & & \\
\hline
\end{tabular}

Table 4. Review process of four urbanization index with Light Index and VFC dynamically.

\begin{tabular}{cccccc}
\hline Year & Built Up\% & Non-Agriculture $\%$ & City People $\%$ & Light Index & Mean of VFC \\
\hline 2000 & 7.946035 & 0.908174561 & 0.31185087 & 6.550127 & 0.771992243 \\
2001 & 8.246380 & 0.917865316 & 0.483484 & 6.576184 & 0.751397295 \\
2002 & 7.723105 & 0.924822365 & 0.31131984 & 6.631324 & 0.7859657 \\
2003 & 8.449690 & 0.932284987 & 0.45898521 & 6.207175 & 0.802379114 \\
2004 & 9.367759 & 0.933813138 & 0.46808091 & 7.70958 & 0.794303438 \\
2005 & 8.136325 & 0.936682778 & 0.45834674 & 6.24091 & 0.772397392 \\
2006 & 8.490129 & 0.942373107 & 0.49219358 & 7.152527 & 0.786137155 \\
2007 & 9.226987 & 0.946642 & 0.51791855 & 8.261293 & 0.79177311 \\
2008 & 9.570085 & 0.946380 & 0.51387329 & 8.281494 & 0.775227335 \\
2009 & 9.875050 & 0.949085 & 0.5209 & 7.642869 & 0.823068354 \\
\hline
\end{tabular}

0.772397392\% in 2005 and again with a further increasing are 10.285029\%, 0.950297155\%, 0.5215\%, $9.885368 \%$ and $0.776052754 \%$ in 2010 entirely.

In this study times series analysis includes sequence plot of VFC and Light Index modelling as Figure 10, time series modelling as Figure 11, $\mathrm{ACF}^{1}$ and $\mathrm{ACF}$ partial ${ }^{2}$ modelling for Light Index as Figure 12. According to Figures 5-9 and also Tables 2-4, was explained that both trends of VFC and Light Index are increasing and have upward position whether or not. According to Figure10 in the bottom, this topic be repeated here but with important difference that VFC and Light Index have strong inverse relationship with each other, therefore it is very clear that by increasing Light Index, VFC decreased in most cases defiantly.

In fact we can conclude any socio-economic activity such as urbanization, urban development and increasing population density affected VFC in the whole period from 2000 to 2010 in the study area. Also in Figure 10, perhaps we see a small amount of harmony between VFC and Light Index in 2005 and 2006 that each one has its own ecological and socio-economic reasons totally. Figure 11 shows Time Series Modelling of Light Index. The graph in Figure 11, there is strong evidence of our result based on increasing Light Index and growing urban development annually and more confirms our previous results.

Figure 12 shows ACF and partial ACF modelling of Light Index in a time interval approximately 11 years. Amounts of Light Index are at roughly situated between ranges -0.5 to 0.5 , and vertical axis of ACF and partial ACF show this range well. Also chart has taken harmonious state in positive and negative directions but with equal amounts, thus it can be concluded Light Index has suitable thoroughness altogether and in this paper it could be appropriate index for evaluating VFC and VFC change dynamic annually.

\footnotetext{
${ }^{1}$ Autocorrelation coefficient.

${ }^{2}$ Partial autocorrelation coefficient.
} 


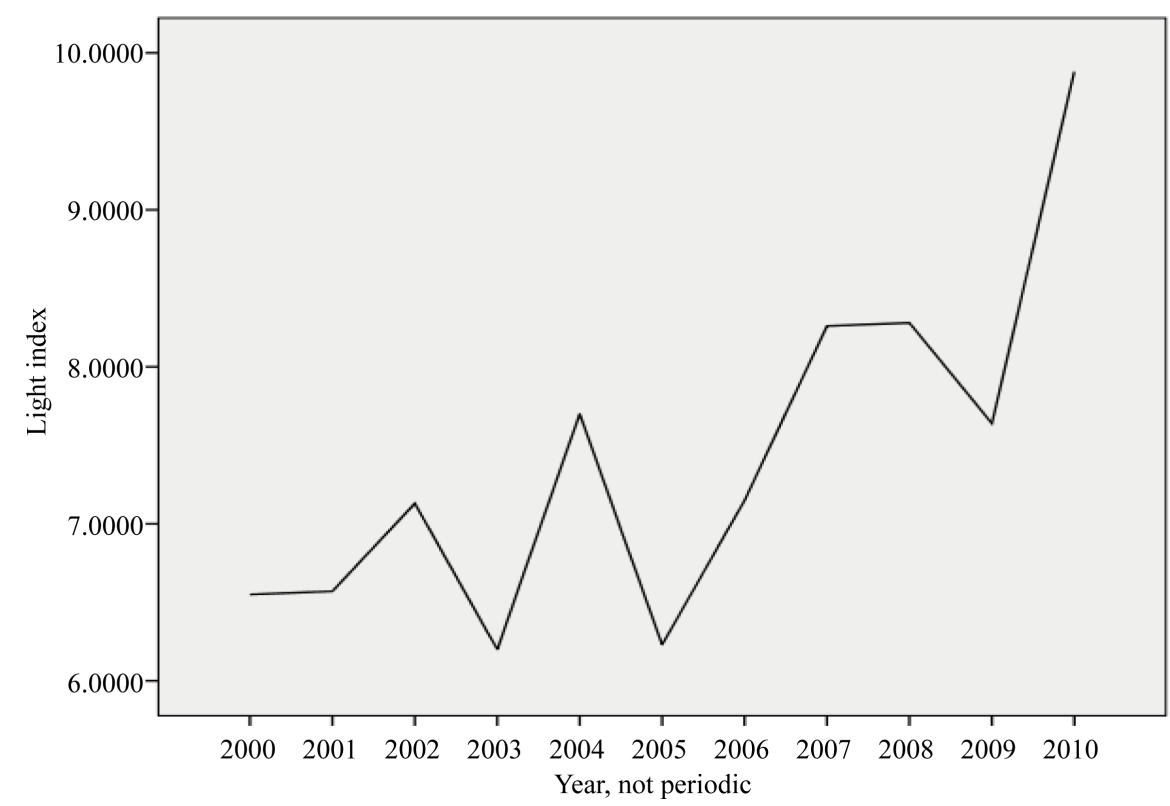

(a)

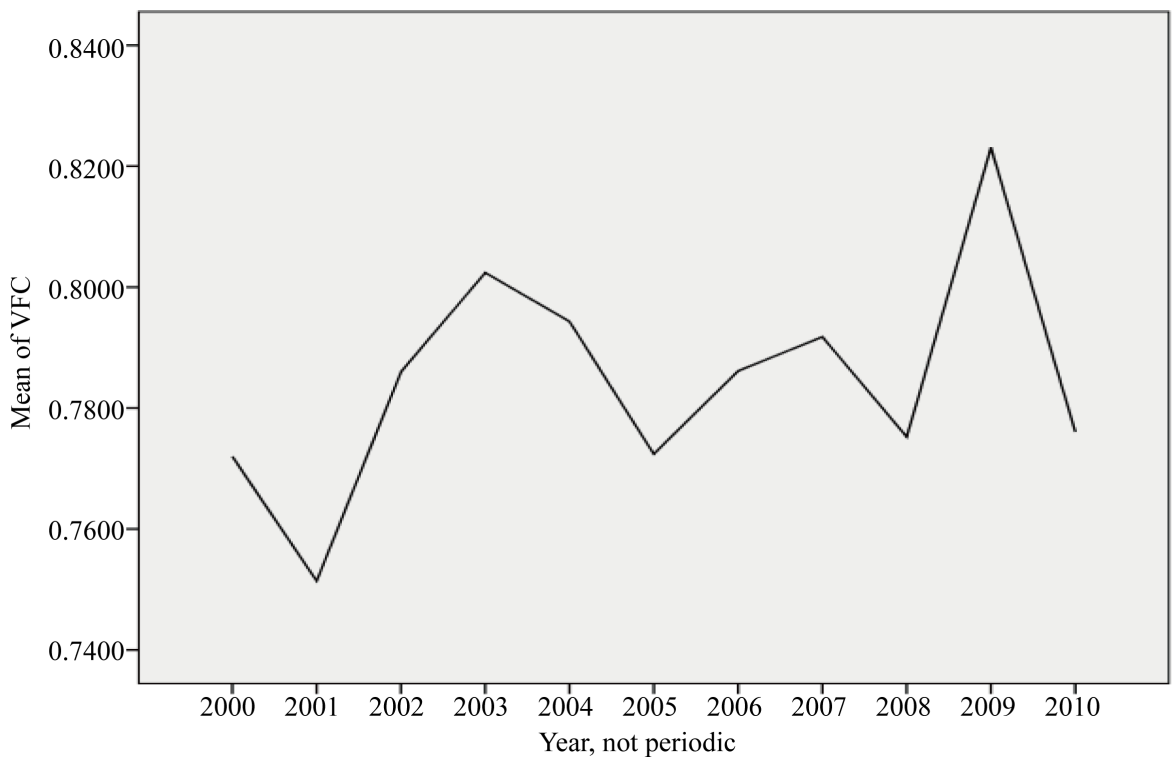

(b)

Figure 10. Sequence plot of Mean of VFC and Light Index.

\subsection{Driving Forces of VFC Variation}

In previous theoretical arguments and field survey we assume that the vegetation fractional cover in the study area is significantly affected by human socio-economic activities as urbanization, development urban and expending rural area and increasing population density. Also was identified the potential of DMSP data for estimating urban population as well as the technical to monitor urban population dynamics annually in a region where data are scare and the demographic dynamic are unique. Altogether in our study results showed Light Index obtained from DMSP/OLS images enables to use as an indicator to detect human presence and socioeconomic activities for analysis of the spatial-temporal patterns in most parts of the developing countries. On the other hands we argue that variation of VFC is indeed driven by human socio-economic factors and results of Figures 6-10 and Figure 13, and in addition Tables 2-4 confirmed the accuracy of this issue properly. Accord- 


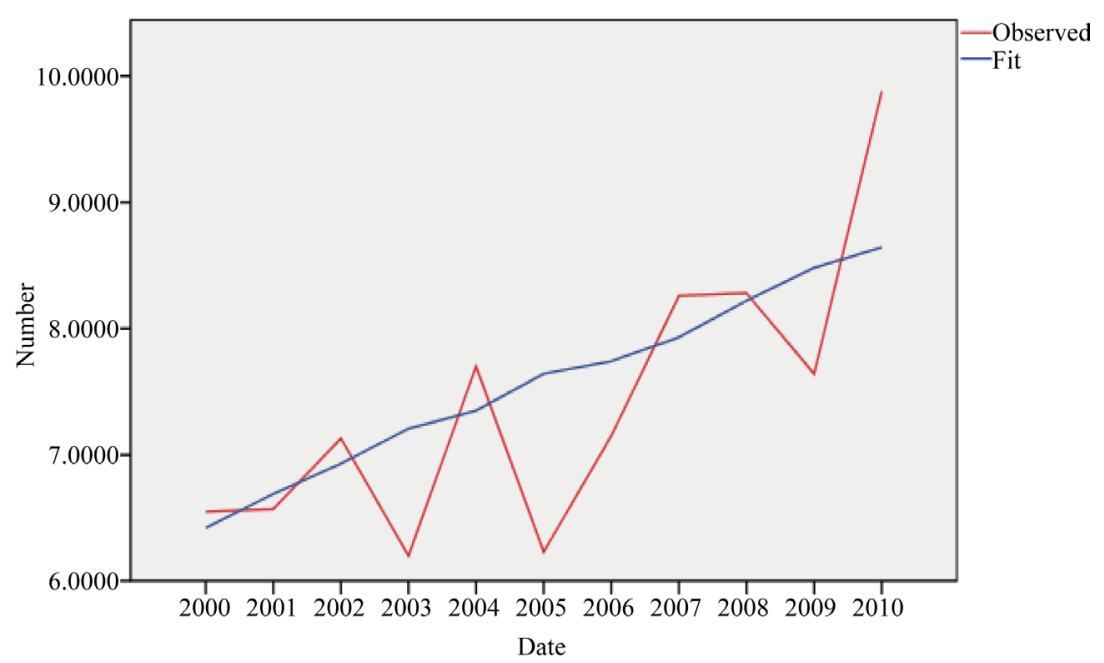

Figure 11. Time series modeling of Light Index.
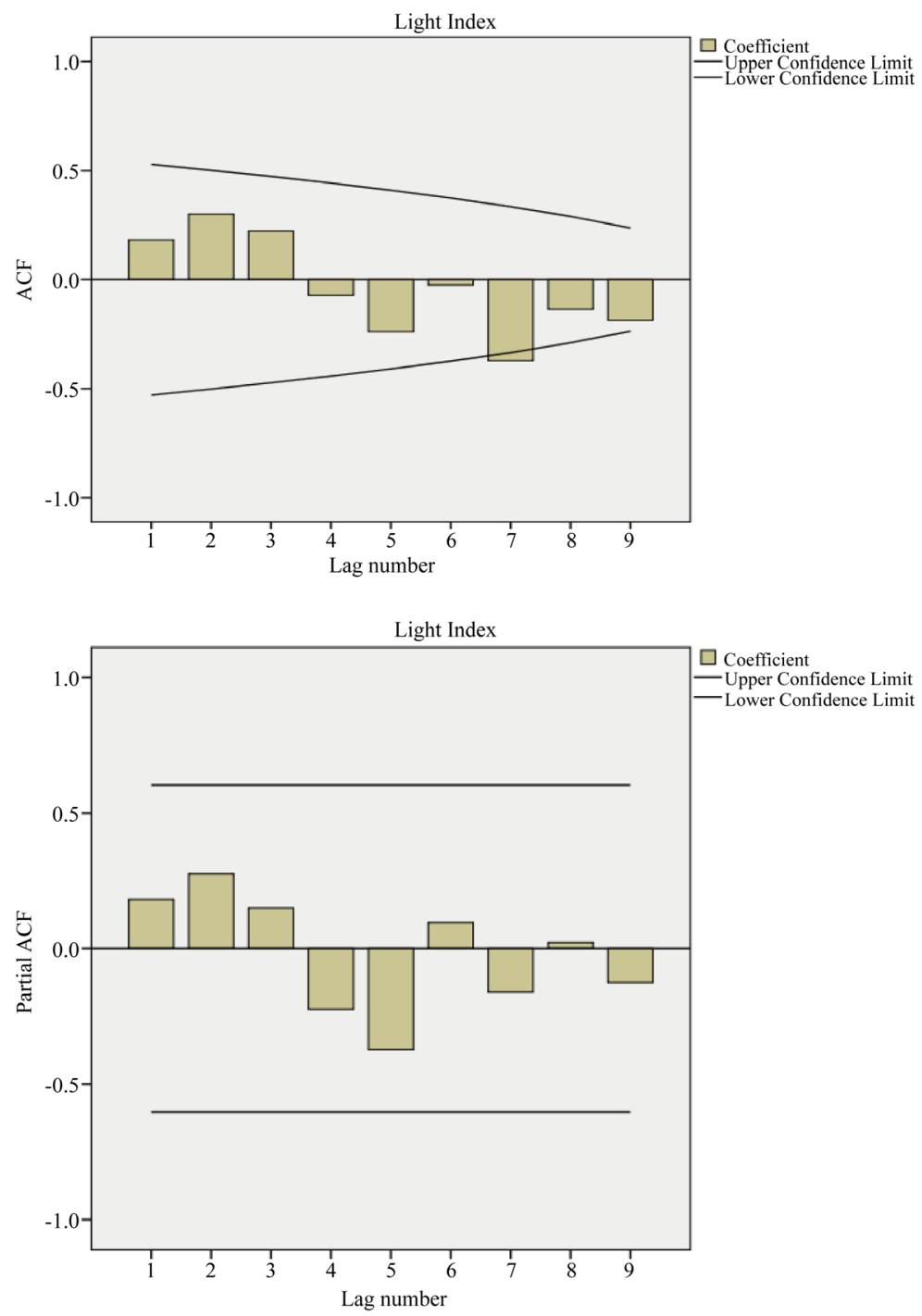

Figure 12. Autocorrelation and partial autocorrelation modelling of Light Index. 

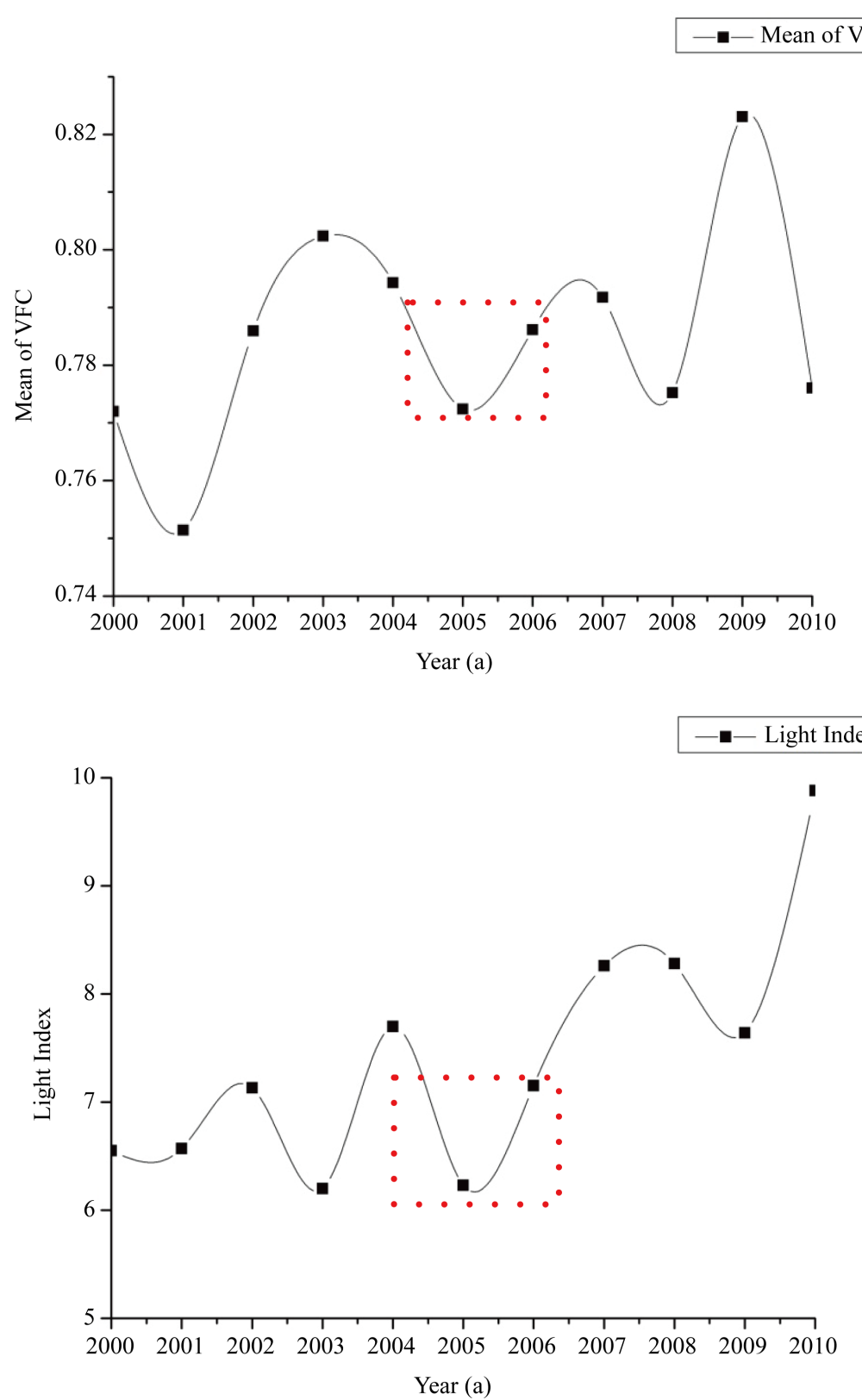

Figure 13. Dynamics annually of VFC and Light Index in Guangdong province from 2000 to 2010.

ing to Figure 13, this assumption acknowledges there is strong inverse relationship among VFC and Light Index. For example Figure 13, shows at the beginning of period in 2000 and 2001 that with increasing Light Index, VFC decrease. This trend continues to 2005. But on the other side, Figure 13 shows the trends of VFC and Light Index has same direction in 2005-2006 (marked with dotted red), Because Guangdong province had a major shift in its population between the years of 2005 and 2006, So that scientific resources report that Guangdong had surpassed Henan and Sichuan province to become the most populous province in China in January 2005, registering 79.1 million permanent residents and 31 million migrants who lived in the province for at least six months of the year [22]. Thus, it can be concluded that increasing and decreasing population density leads to change VFC undoubtedly. In fact in Figure 13, the trend of Light Index must was decreased in 2005 to 2006 and was found inverse direction with VFC actually [1]. They were concluded in general, deforestation is highly correlated with the logarithm of population density. Again the trends of VFC and Light Index have inverse rela- 
tionship together in 2007 to 2010. Figure 13 shows sharp decline of VFC and sudden increase of Light Index in 2009 to 2010 actually. In fact we face with the most increasing of human activity in 2009 to 2010 surly and on the other hand forest protection and grassland improvement has been on the decline. Indeed during the more than 10 years, the population of Guangdong Province increased from 85,225,007 people in 2000 to 104,303,132 person in 2010. With the increase of the population, human activities such as urbanization, development of rural areas and land utilization increase additionally and this issue will affects vegetation fractional cover. But human activities such as agriculture production, ecological construction significantly drove the improvement of vegetation cover [8]. In addition with development of social economy, people become increasingly aware of the importance of environmental protection and sustainable development to restore forestland or grassland [19]. According to Figure 13, VFC increases in 2001 to 2003, in 2005 to 2007 and eventually 2008 to 2009. In can be concluded that beside to reducing of human activities and diminishes Light Index in these years, driven by ecological benefits in the recent years, reforestation, rangelands improvement and other ecological project have been increasing. Also controlling land use, planting trees and agroforestry were closely related to expand VFC and improve vegetation coverage in the study area. Additionally, it cannot be ignored impacts of climatic factors and physiographic with VFC variation annually [23]. They also were reported that vegetation index and fractional vegetation cover have good correlation with climate variables such as precipitation, temperature and evaporation [8]. They were concluded the average VFC increased from $40.17 \%$ in 1989 to $53.6 \%$ in 2006 mainly due to the increase of temperature, annual runoff and population as well as improved land utilization. Howsoever we faced with seven years increasing of VFC and four years decreasing of VFC from 2000 to 2010 in the study area. It was found that the VFC in Guangdong province shows an increasing trend in the 11 years.

\section{Conclusion}

We could use the Modis NDVI images and DMSP/OLS datasets to establish models for linking Vegetation Fractional Cover with the Light Index, to predict forest cover changes of Guangdong province in the period of 2000 to 2010 dynamically. We calculated VFC levels with four classes as level I, level II, level III and IV with the pre-specified values including low percentage of VFC ( $<50 \%)$, medium percentage of VFC $(50 \%-70 \%)$, high percentage of VFC (70\% - 90\%) and very high percentage of VFC (>90\%) respectively. In this way, the major changes of VFC were defined annually and were shown degraded and healthy vegetation areas by all levels of VFC completely. We could obtain areas with level I, had lowest annual changes and areas with level IV, and had highest rate among all. Herein, Moran's I statistic ruled that during the years of 2000, 2002, 2007 and 2009, human activities have been increased and that deforestation was dominated in some parts of the study area, but fortunately in the period of 2001, 2003, 2006, 2008 and 2010, we witnessed reforestation and ecological protection with reduction of human activities. In addition, spatial and temporal changes of VFC with Hot Spot-Cold Spot maps and Light Index were restated that major changes with reduction of forest cover caused by human activities were related to central-southern parts and coastal areas of the study area in the periods of 2000-2005, and on the other side we could demonstrate that north parts, east and west areas with high and very high percentage of forest cover, had less changes in this period fortunately. Also with the help of mentioned indicators, we could show degradation caused by human activates had great reduction, and VFC could concentrate in the north and specially east areas in the period of 2005-2010. In fact, the process of increasing VFC was successful in this period of our study, although we saw increasing human activities. Indeed development of social economy had increasingly aware of the importance of environment protection and also driven by ecological benefits followed reforestation and to restore land correctly. We evaluated time series modelling of VFC and Light Index and we described that both trends of VFC and Light index were increasing and that they had upward process with acceptable inverse relationship together. Results of time series modelling as sequence plot and time series modeller ruled that by increasing Light Index, VFC decreased in some areas and we concluded that socio-economic activity was affected VFC definitely. Prediction of ACF modelling of times series modelling subsumed that Light Index was suitable indicator to monitor forest cover changes annually and CCF modelling confirmed the accuracy of relationship among VFC and Light Index additionally. Besides, driving forces related vegetation fractional cover was also showed, whereas we could focus on changes caused by human activates based on DMSP/OLS datasets and Light Index trend. As well as we predicted trends of increasing and decreasing of population density that was leaded to change VFC in our study area. As a matter of fact, we demonstrated that forest cover change was highly correlated with the logarithm of changes in population. As a consequence, 
an advantage of our approach is that it also allows testing alternative definitions of VFC and Light index together dynamically. Our study provided the first Guangdong province wide maps showing the spatial patterns, Hot Spot and Cold Spot and some of the evaluation indicators of forest coverage change detection based on the dense time series of DNVI images in relation to DMSP/OLS nighttime observations. However, it highlights the dynamic nature of forest coverage changes and human activities need for frequent monitoring of all lands in order to assess the forest areas, woodless areas and degraded areas. These findings will be important for inferring the efficacy of forest resources management and for analyzing causal relationship between socio-economic drivers and forest coverage changes.

\section{Acknowledgements}

The valuable suggestions made by anonymous referees are gratefully acknowledged. "This work was supported by the Natural Science Foundation of China under Grant 31170592”.

\section{References}

[1] Pahari, K. and Murai, Sh. (1999) Modelling of Prediction of Global Deforestation Based on the Growth of human Population. Journal of Photogrammetry and Remote Sensing, 54, 317-324. http://dx.doi.org/10.1016/S0924-2716(99)00032-5

[2] Chand, T.R.K., Badarinath, K.V.S. and Prasad, V.K. (2006) Monitoring Forest Fires over the Indian Region Using Defence Meteorological Satellite Program-Operational Linescan System Nighttime Satellite Data. Remote Sensing of Environment, 103,165-178. http://dx.doi.org/10.1016/j.rse.2006.03.010

[3] Potapov, P.V., Turubanova, S.A., Tyukavina, A., et al. (2015) Eastern Europe’s Forest Cover Dynamic from 1985 to 2012 Quantified from the Full Landsat Archive. Remote Sensing of Environment, 159, 28-43. http://dx.doi.org/10.1016/j.rse.2014.11.027

[4] Hyung, K.D., Sexton, J.O., Noojipady, P., et al. (2014) Global, Landsat-Based Forest-Cover Change from 1990 to 2000. Remote Sensing of Environment, 155, 178-193. http://dx.doi.org/10.1016/j.rse.2014.08.017

[5] Burgess, R., Hansen, M., Olken, B.A., Potapov, P. and Sieber, S. (2012) The Political Economy by Multi-Temporal Classification across the Landsat-5 Record. Remote Sensing of Environment, 128, 246-258.

[6] Sexton, J.O., Urban, D.L., Donohue, M.J. and Song, C. (2013) Long-Term land Cover Dynamics of Deforestation in the Tropics. Quarterly Journal of Economics, 127, 1707-1754.

[7] Moderate Resolution Imaging Spectroradiometer. http://modis.gsfc.nasa.gov/

[8] Zhang, F., Tiyip, T., Ding, J.L., et al. (2013) Vegetation Fractional Coverage Change in a Typical Oasis Region in Tarim River Watershed Based on Remote Sensing. Journal of Arid Land, 5, 89-101. http://dx.doi.org/10.1007/s40333-013-0145-3

[9] Liu, J., Yin, S., Zhang, G.S., et al. (2009) Dynamic Change of Vegetationcoverage of Mu Us Sandland over the 17 Years by Remote Sensing Monitor. Journal of Arid Land Resources and Environment, 23, 162-167.

[10] Ju, W., Zhujun, G., Li, L., et al. (2013) Using Vegetation Indices and Texture Measures to Estimate Vegetation Fractional Coverage (VFC) of Planted and Natural Forests in Nanjing City, China. Advances in Space Research, 51, 11861194. http://dx.doi.org/10.1016/j.asr.2012.11.015

[11] Kharol, Sh.K., Badarinath, K.V.S. and Roy, P.S. (2008) Studies on Emissions from Forest Fires Using Multi-Satellite Datasets over North East Region of India. The International Archives of the Society for Photogrammetry and Remote Sensing. ISPRS Archives-Volume XXXVII Part B8.

[12] Amaral, S., Monteiro, A.M.V., Camara, G. and Quintanilha, J.A. (2006) DMSP/OLS Nigh-Time Light Imagery for Urban Population Estimates in the Brazilian Amazon. International Journal of Remote Sensing, 27, 885-870. http://dx.doi.org/10.1080/01431160500181861

[13] Huang, Q., Yang, X., Gao, B., et al. (2014) Application of DMSP/OLS Night Images; A Meta-Analysis and a Systematic Literature Review. Remote Sensing, 6, 6844-6866. http://dx.doi.org/10.3390/rs6086844

[14] China National Human Development Report (2013) UNDP China and Institute for Urban and Environmental Studies. Chinese Academy of Social Sciences, Beijing.

[15] Guan, D., Wang, G., Peart, M.R., et al. (2013) Ecosystem Carbon Stocks of Mangrove Forest in Yinglio Bay, Guangdong Province of South China. Forest Ecology and Management, 310, 539-546. http://dx.doi.org/10.1016/j.foreco.2013.08.045

[16] Nasa Earth Ovservation. http://neo.sci.gsfc.nasa.gov/ 
[17] Estel, S., Kuemmerle, T., et al. (2015) Mapping Farmland Abandonment and Recultivation across Europe Using MODIS NDVI Time Series. Remote Sensing and Environment, 163, 312-325.

http://dx.doi.org/10.1016/j.rse.2015.03.028

[18] Defense Meteorological Satellite Program (DMSP). http://www.ngdc.noaa.gov/eog/re_direct.html

[19] Li, H., Lu, Z.L., Li, D.Z., et al. (2009) Estimation and Monitoring of Vegetation Coverage Dynamics in Chongming County of Shanghai by RS Method. Urban Environment \& Urban Ecology, 22, 8-11.

[20] Wei, Y., Liu, H., Song, W., Yu, B. and Xiu, C. (2014) Normalization of time Series DMSP-OLS Nighttime Light Images for Urban Growth Analysis with Pseudo Invariant Features. Landsc. Urban Plan, 128, 1-13. http://dx.doi.org/10.1016/j.landurbplan.2014.04.015

[21] Zhang, Q., Schaaf, C. and Seto, K.C. (2013) The Vegetation Adjusted NTL Urban Index: A New Approach to Reduce Saturation and Increase Variation in Nighttime Luminosity. Remote Sensing of Environment, 129, 32-41. http://dx.doi.org/10.1016/j.rse.2012.10.022

[22] Guangdong Province. https://en.wikipedia.org/wiki/Guangdong

[23] Yang, G.H., Bao, A.M., Chen, X., et al. (2010) Vegetation Cover Change with Climate and Land Use Variation along Main Stream of Tarim River. Journal of Desert Research, 30, 1389-1397. 